\title{
Clonorchiasis sinensis detected by laparoscopic exploration of biliary tracts in two patients with obstructive jaundice
}

\author{
Xialei Liu ${ }^{1 \dagger}$, Genglong Zhu ${ }^{1 \dagger}$, Chaonong Cai ${ }^{1}$, Zhiyue $\mathrm{Lv}^{2,3,4^{*}}$ and Jian $\mathrm{Li}^{{ }^{*}}$
}

\begin{abstract}
Background: Hepatic clonorchiasis is one of the most prevalent food-borne parasitic diseases worldwide. Clonorchis sinensis, the pathogen, is the major parasitic trigger contributing to cholangitis, cholelithiasis, and even cholangiocarcinoma. Unfortunately, unspecific clinical manifestations of patients with hepatic clonorchiasis tend to mislead clinicians to neglect or misdiagnose them, following ignorance of appropriate therapy. Our case report may shed light on definite diagnosis of clonorchiasis with concomitant cholelithiasis, methodology for surgical drainage of the parasites, and postoperative anthelmintic therapy.

Case presentation: Two patients with habit of eating infected raw or undercooked freshwater fish were hospitalized due to right upper quadrant pain and jaundice. Magnetic resonance cholangiopancreatography (MRCP)/computed tomography (CT) detection indicated cholangiolithiasis and cholangiolithiasis with concurrent cholecystolithiasis, respectively. Fecal examinations were both negative for adult worms or eggs of parasites. However, adults of Clonrochis sinensis were detected within hepatobiliary tracts during laparoscopic cholecystectomy. Postoperative drainage and anthelmintic therapy contributed to complete recovery with good prognosis.

Conclusions: Clonorchiasis provokes cholangiolithiasis and cholecystolithiasis. Standardized treatments for these gallstone patients with concomitant clonorchiasis include surgical removal of the calculus, postoperative T tubule drainage and anthelmintic therapy. Serological test or polymerase chain reaction (PCR)-based approaches might be helpful for diagnosis of clonorchiasis when no eggs are found by stool microscopy. Public health promotion on ceasing to eat raw freshwater fish is essential for prevention and control of clonorchiasis.
\end{abstract}

Keywords: Clonorchiasis, Obstructive jaundice, Gallstone

\section{Background}

Clonorchiasis, a serious foodborne zoonotic disese endemic in the Far East including China, Korea, Japan, and Vietnam, is caused by the pathogen Clonorchis sinesis (C. sinensis), which is mainly located within the intrahepatic ducts of patients. Humans can acquire the infection by ingesting raw or undercooked freshwater fish containing metacercariae [1-3]. However, the symptoms of hepatic clonorchiasis, including abdominal pain,

\footnotetext{
* Correspondence: Ivzhiyue@mail.sysu.edu.cn; lijian5@mail.sysu.edu.cn

${ }^{+}$Xialei Liu and Genglong Zhu contributed equally to this work.

${ }^{2}$ Zhongshan School of Medicine, Sun Yat-sen University, Guangzhou 510080, China

${ }^{1}$ Department of Hepatobiliary, the Fifth Affiliated Hospital of Sun Yat-sen University, Zhuhai 519000, China

Full list of author information is available at the end of the article
}

nausea, anorexia, diarrhea, obstructive jaundice, and even pyogenic cholangitis, dispaly unspecific $[4,5]$. Thus, it is hard to diagnose early until stool examination for eggs or worms harvested from the biliary tract during surgery. In this case report, we presented two cases of unspecific hepatobiliary manifestations of $C$. sinensis infection.

\section{Case presentation \\ Case 1}

A 49-year-old man complained of right upper quadrant abdominal pain and jaundice for 2 days and was hospitalized in the Fifth Affiliated Hospital of Sun Yat-sen University. The pulse rate of the patient was regular and the temperature and blood pressure were normal. The patient had a clear dietary history of eating raw

(c) The Author(s). 2019 Open Access This article is distributed under the terms of the Creative Commons Attribution 4.0 International License (http://creativecommons.org/licenses/by/4.0/), which permits unrestricted use, distribution, and reproduction in any medium, provided you give appropriate credit to the original author(s) and the source, provide a link to the Creative Commons license, and indicate if changes were made. The Creative Commons Public Domain Dedication waiver (http://creativecommons.org/publicdomain/zero/1.0/) applies to the data made available in this article, unless otherwise stated. 
freshwater fish, however, no eggs of parasites were detected in the stool specimen by direct smear method (each specimen was smear onto 3 labeled slides). Magnetic Resonance Cholangiopancreatography (MRCP) revealed obstruction of the common bile duct by a stone with obviously diffuse dilation of intrahepatic ducts (Fig. 1). Initial laboratory data indicated obstruction jaundice and liver enzymes elevation (Table 1). Considering that the cholangitis was caused by the common bile duct stone, the gallbladder stone and cholecystitis, The laparoscopic cholecystectomy and laparoscopic common bile duct exploration was performed. A flat, leaf-like worm was found under the choledochoscope at the extremitas inferior common bile duct during the operation (Fig. 2). After the surgery, a "T" shape catheter was inserted into the common hepatic duct to establish drainage. A course of anthelmintic therapy (albendazole: $16 \mathrm{mg} / \mathrm{kg} /$ day for 4 days) was administrated. During the subsequent days, the adult worms were observed in the bile duct through the " $\mathrm{T}$ " shape catheter. The pain of the patient relieved totally, the jaundice faded gradually and liver function indices were nearly normal.

\section{Case 2}

A 40-year-old female patient had suffered from upper quadrant abdominal pain, with occasional nausea and fever for more than 2 years. The patient was diagnosed as cholecystitis at another hospital nearby and felt relieved very soon after treatment in the past 2 years. She came to the hospital 11 days ago due to the severe upper quadrant abdominal pain recurred with severe jaundice. Complete medical examinations, including blood pressure, pulse
Table 1 Pre-treatment blood results of 2 patients

\begin{tabular}{|c|c|c|c|}
\hline \multirow[t]{2}{*}{ Variable } & \multicolumn{2}{|l|}{ Value } & \multirow[t]{2}{*}{ Reference value } \\
\hline & Patient 1 & Patient 2 & \\
\hline \multicolumn{4}{|l|}{ Hematology } \\
\hline Leukocytes & $5.55 \times 10 \wedge 9 / L$ & $8.05 \times 10 \wedge 9 / L$ & $3.5-9.5 \times 10 \wedge 9 / L$ \\
\hline Neutrophil & $59.60 \%$ & $57.30 \%$ & $40-75 \%$ \\
\hline Lymphocyte & $27.40 \%$ & $20.70 \%$ & $20-50 \%$ \\
\hline Monocyte & $6.50 \%$ & $6.60 \%$ & $3-10 \%$ \\
\hline Eosinophils & $6.50 \%$ & $15.40 \%$ & $0.4-8.0 \%$ \\
\hline Basophils & $0.00 \%$ & $0.00 \%$ & $0-1 \%$ \\
\hline Erythrocytes & $5.49 \times 10^{\wedge} 12 / L$ & $4.66 \times 10 \wedge 12 / L$ & $3.8-5.8 \times 10^{\wedge} 12 / \mathrm{L}$ \\
\hline Hemoglobin & $159 \mathrm{~g} / \mathrm{L}$ & $143.0 \mathrm{~g} / \mathrm{L}$ & $115-175 \mathrm{~g} / \mathrm{L}$ \\
\hline Hematocrit & $47.10 \%$ & $42.90 \%$ & $35-50 \%$ \\
\hline Platelets & $190 \times 10^{\wedge} 9 / \mathrm{L}$ & $230 \times 10^{\wedge} 9 / \mathrm{L}$ & $125-350 \times 10^{\wedge} 9 / L$ \\
\hline \multicolumn{4}{|l|}{ Blood chemistry } \\
\hline AST & $83.00 \mathrm{U} / \mathrm{L}$ & $182.00 \mathrm{U} / \mathrm{L}$ & 13-40 U/L \\
\hline ALT & $236.00 \mathrm{U} / \mathrm{L}$ & 399.00 U/L & 7-50 U/L \\
\hline$y-G T P$ & $848.00 \mathrm{U} / \mathrm{L}$ & $419.00 \mathrm{U} / \mathrm{L}$ & $10-60 \mathrm{U} / \mathrm{L}$ \\
\hline Total bilirubin & $128.80 \mu \mathrm{mol} / \mathrm{L}$ & $129.20 \mu \mathrm{mol} / \mathrm{L}$ & 3-24 $\mu \mathrm{mol} / \mathrm{L}$ \\
\hline Direct bilirubin & $92.20 \mathrm{mmol} / \mathrm{L}$ & $96.90 \mathrm{mmol} / \mathrm{L}$ & 0-8.0 mmol/L \\
\hline ALP & $315 \mathrm{U} / \mathrm{L}$ & $315 \mathrm{U} / \mathrm{L}$ & $45-125 \mathrm{U} / \mathrm{L}$ \\
\hline TBA & $233.00 \mu \mathrm{mol} / \mathrm{L}$ & $242.90 \mu \mathrm{mol} / \mathrm{L}$ & $0-10 \mu \mathrm{mol} / \mathrm{L}$ \\
\hline
\end{tabular}

Abbreviations: ALT alanine aminotransferase; AST aspartate aminotransferase; Y-GTP, gamma-glutamyl transpeptidase; ALP alkaline phosphatase; TBA total bile acid

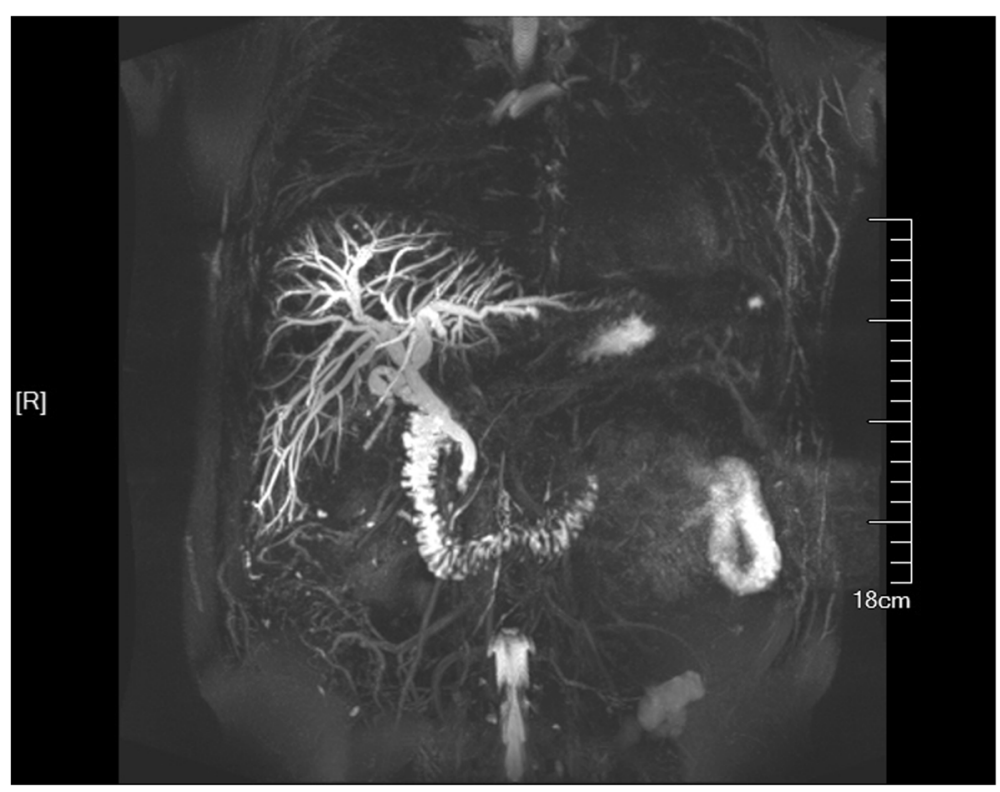

Fig. 1 Dilation of the intrahepatic ducts by MRCP 

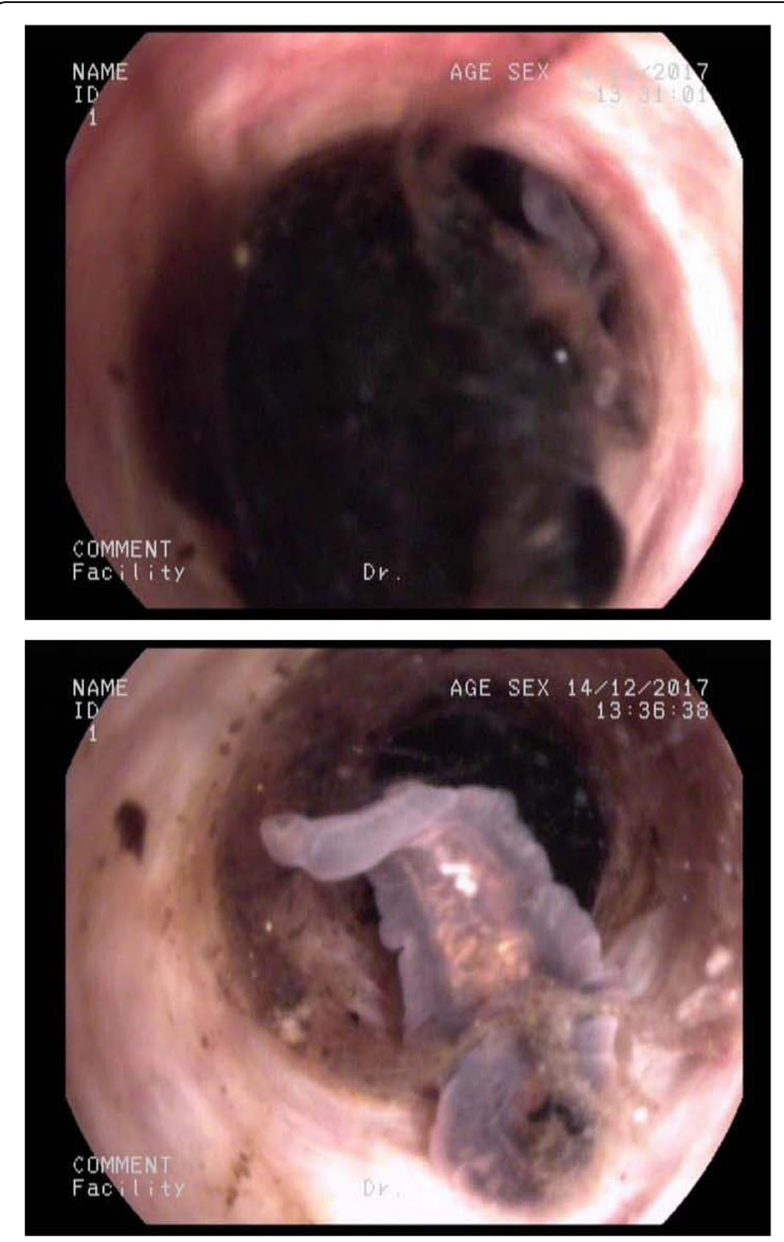

Fig. 2 Examination of the stone and the worms in common bile duct by the choledochoscope during operation rate, temperature and physical examination of the abdomen, were performed in the Fifth Affiliated Hospital of Sun Yat-sen University. The clinical examinations revealed that the pulse rate, temperature and blood pressure were normal. Stool microscopy for parasite eggs by direct smear method were negative 3 times. Computed tomography (CT) scan revealed obstruction of the bile duct with dilation of the intrahepatic ducts which suggested a retained bile duct stone and a gallbladder stone (Fig. 3). Laboratory data indicated obstruction jaundice, peripheral eosinophilia and liver enzymes elevation (Table 1). Detailed inquiry revealed she had a history of eating raw freshwater fish. A clinical diagnosis of acute cholangitis and cholecystitis was made and laparoscopic cholecystectomy and laparoscopic common bile duct exploration was performed. Many flat, leaf-like worms appeared under the choledochoscope as deep bile duct cannulation (Fig. 4 and Fig. 5). Besides, many nodules distributed dispersedly among the surface of the liver (Fig. 6). After the operation, the " $\mathrm{T}$ " shape catheter was placed in the common hepatic duct to allow patent drainage. The patient was treated with anthelmintic therapy (albendazole: $16 \mathrm{mg} / \mathrm{kg} /$ day for 4 days). More C. sinensis worms were drained through the "T" shape catheter (Fig. 7). The clinical status of the patient improved gradually without the pain recurring.

\section{Discussion and conclusions}

Clonorchiasis is the most common fluke infection in East Asian population with approximately 35 million infected individuals $[6,7]$. The encysted larvae of the parasites invade the hosts mostly by the consumption of raw freshwater fish and crustaceans, release in the duodenum, migrate into the bile ducts and develop into adults within the host's intrahepatic ducts [8]. C. sinensis infection is primarily related to liver and biliary tract disorders and

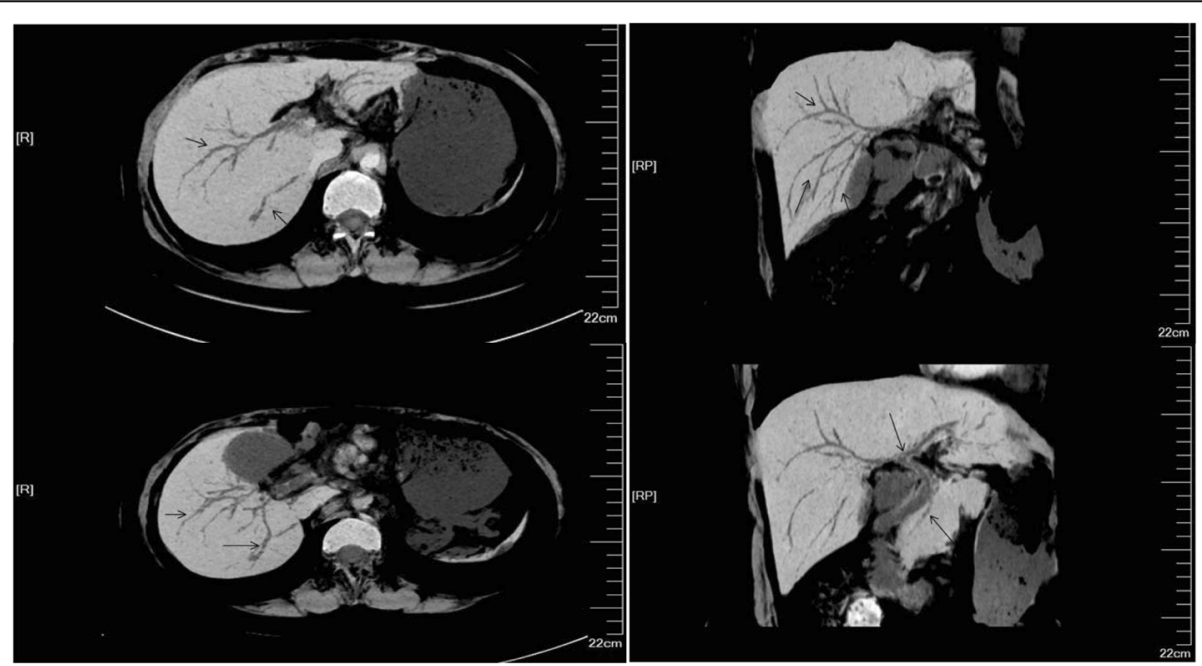

Fig. 3 Dilation of the intrahepatic ducts by CT scan 


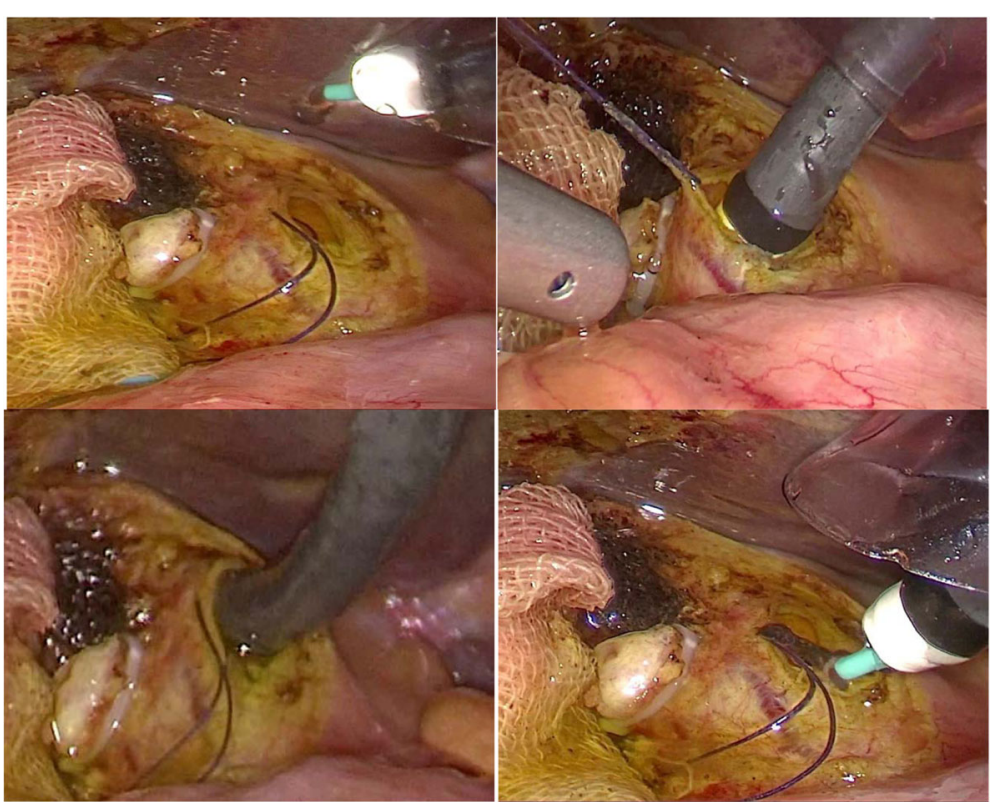

Fig. 4 Laparoscopic view of the operation

considered as the etiological agents of cholangiocarcinoma 11-9]]. However, the clinical manifestations of hepatic clonorchiasis are usually unspecific, including nausea, anorexia, diarrhea (with moderate infestation), right upper quadrant abdominal pain, obstructive jaundice, tender hepatomegaly and pyogenic cholangitis (with severe infestation) and mild infestation is asymptomatic [12-14], so it's easy to be neglected or misdiagnosed.
Some incidental diagnosis is suspected due to discovery of ova on routine stool examination. Although our patients had the history of eating inadequate cooked freshwater fish, the negative results of stool examination for eggs in the present study might resulted from the low rates of egg detection in the feces [15], and determination of C. sinensis DNA in feces by real-time fluorescent PCR [16] or serological

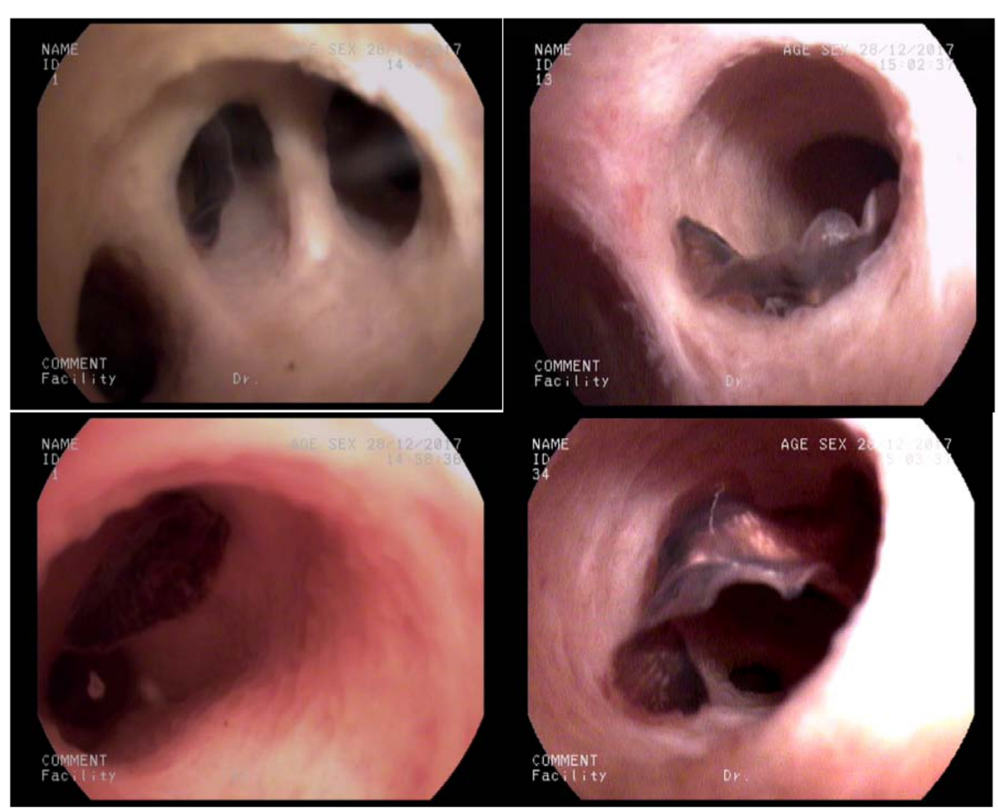

Fig. 5 Choledochoscope view of worms inside the bile duct 


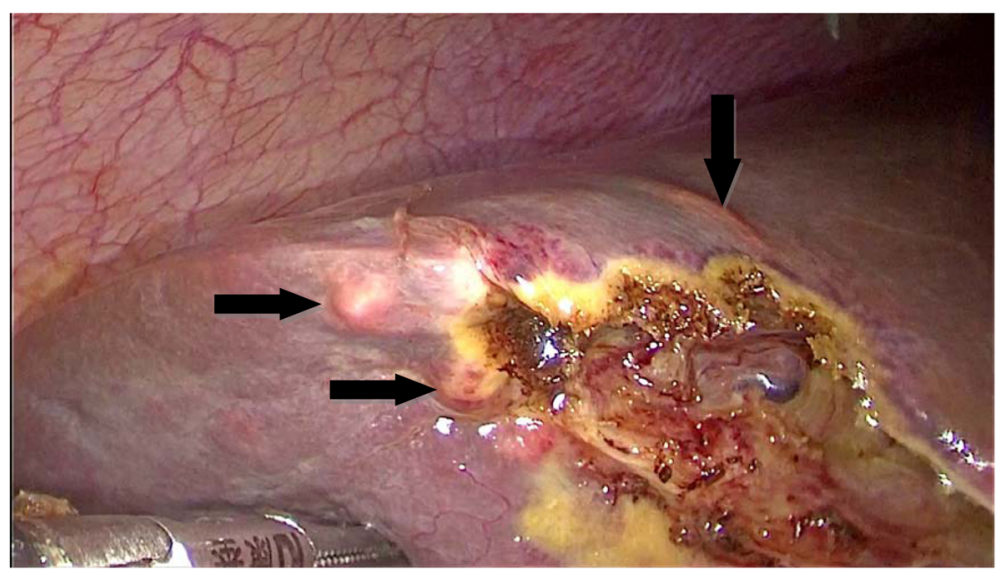

Fig. 6 Nodules (indicated by arrows) distributed on the surface of the liver

test for C. sinensis - specific antibodies will increase the sensitivity and hence contributes to the diagnosis $[17,18]$.

Administration of anthelmintic medication, albendazole (an effective alternative of praziquantel), is the primary treatment for clonorchiasis [19, 20]. Meanwhile, when

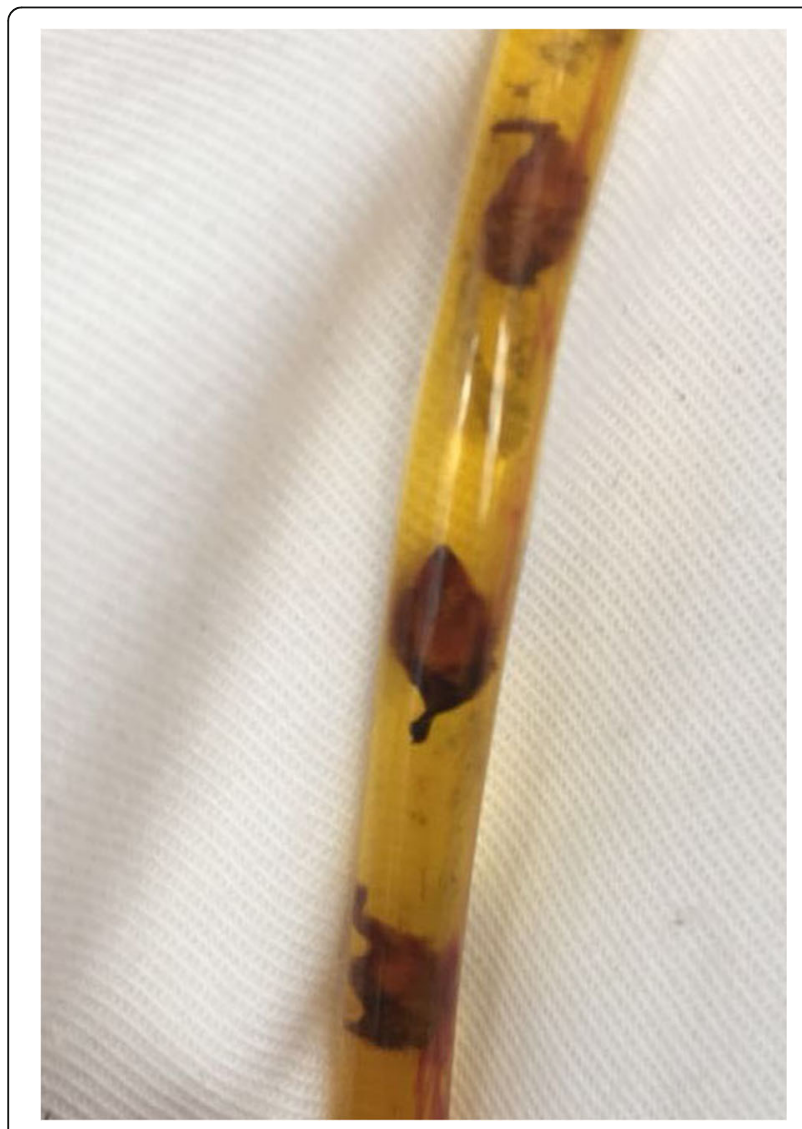

Fig. 7 C. sinensis worms drained through the catheter there is biliary obstruction caused by the worm directly or indirectly, the operation is necessary. In the present study, both of the two patients had acute cholangitis with presentation of pain and obstructive jaundice which most likely resulted from the bile duct obstruction by a mass of adults of $C$. sinensis [21]. The worms obstructed the biliary tree and served as a nidus for biliary tract stones formation. Therefore, presence of biliary tract stones or bile duct obstruction cannot exclude the possibility of clonorchiasis [22]. Moreover, Long-term infection may result in chronic inflammation and adenomatous hyperplasia of the bile duct which may be a potential risk factor for cholangiocarcinoma $[23,24]$. In the second case, we found numerous nodules which differed from cirrhotic nodules distributed dispersedly on the liver surface during the operation. On examination the nodules had the following characteristics: waxy, immobile, larger volume and the texture equal to the liver. An incisional biopsy of the nodule was performed and the histopathological findings of the excised lesion were consistent with those of the dilated biliary duct cysts caused by clonorchiasis [25]. It reminds the surgeons if similar liver nodules were discovered during the operation, Hepatic clonorchiasis should be considered consciously as one of the possibilities, especially the patients have the history of eating raw freshwater fish. Due to the limited diagnostic value of $\mathrm{CT}$, further investigation points to MRCP, which can clearly outline the caliber, direction and expansion of intrahepatic bile ducts involved [14]. More precise presentation includes minor "cystic" dilatation of peripheral branches of bile ducts, which is quite different from the "homogeneous" dilatation of bile ducts caused by gallstones or tumors. But still it is not significant enough for radiologists to find out the exact pathogen, either the adult worm or the eggs [23]. 
In summary, the clinical symptoms of patients infected by $C$. sinensis are protean. The diagnosis should be suspected when there are following manifestations: recurrent cholangitis, obstructive jaundice, dilation of the intrahepatic ducts without extrahepatic obstruction by CT scan or MRI [26], peripheral eosinophilia, and consumption history of raw freshwater fish. The most effective means to control the disease is to educate people and advertise avoiding eating raw freshwater fish, perhaps [27]. There lacks specific clinical manifestations indicating the accurate diagnosis of hepatic clonorchiasis, partially illustrating why clinicians tend to neglect or misdiagnose it especially as comorbidity in most cases. In a proper epidemiologic context, presence of gallstones and bile duct obstruction can be a sign of clonorchiasis, because even in assymptomatic patients, some of the most common findings in ultrasonography are gallstones and sludge [13, 21].

\section{Abbreviations}

CT: Computed Tomography; MRCP: Magnetic Resonance

Cholangiopancreatography; MRI: Magnetic Resonance Imaging

\section{Acknowledgements}

We sincerely appreciate that the patients agree to publish this study.

\section{Funding}

This work was supported by grants from the Project of Basic Platform of National Science and Technology Resources of the Ministry of Sciences and Technology of China (grant no. TDRC-2017-22), Science and Technology Planning Project of Guangdong Province (grant no. 2016A050502008), the National Key Research and Development Program of China (grant no. 2016YFC1202003, 2016YFC1202005 and 2016YFC1200500), the National Natural Science Foundation of China (grant no. 81371836, 81572023 and 81271855), Guangdong Natural Science Foundation (grant no. 2014A030313134), Science and Technology Planning Project of Guangzhou (grant no. 201607010029), the 111 Project (grant no. B12003), the Undergraduates Innovation Training Program of Guangdong Province (grant no. 201410558274 and 201601084) and Open-ended Fund of Key Laboratory of Tropical Disease Control (Sun Yat-sen Uiversity), Ministry of Education (grant no. 2018kfkt04).

\section{Availability of data and materials}

All data generated or analysed during this study are included in this published paper.

\section{Authors' contributions}

$L X L, Z G L$, and CCN carried out the literature search and drafted the first version of the manuscript. $L J$ and LZY were responsible for designing, coordinating and revising the review. All authors read and approved the final manuscript.

\section{Ethics approval and consent to participate}

All the clinical specimens were obtained with written consent and approved by the Fifth Affiliated Hospital of Sun Yat-sen University Ethics Committee, written consent was obtained from all patients involved in this study.

\section{Consent for publication}

The patients have signed the Consent form and agreed to publish this study and a copy of written Consent is available for the journal.

\section{Competing interests}

The authors declare that they have no competing interests.

\section{Publisher's Note}

Springer Nature remains neutral with regard to jurisdictional claims in published maps and institutional affiliations.

\section{Author details}

'Department of Hepatobiliary, the Fifth Affiliated Hospital of Sun Yat-sen University, Zhuhai 519000, China. ${ }^{2}$ Zhongshan School of Medicine, Sun Yat-sen University, Guangzhou 510080, China. ${ }^{3}$ Key Laboratory of Tropical Disease Control (Sun Yat-sen University), Ministry of Education, Guangzhou 510080, China. ${ }^{4}$ Provincial Engineering Technology Research Center for Biological Vector Control, Guangzhou 510080, China.

Received: 13 August 2018 Accepted: 2 January 2019

Published online: 08 January 2019

\section{References}

1. Lun ZR, Gasser RB, Lai DH, Li AX, Zhu XQ, Yu XB, Fang YY. Clonorchiasis: a key foodborne zoonosis in China. Lancet Infect Dis. 2005;5:31-41.

2. Rim HJ. Clonorchiasis: an update. J Helminthol. 2005;79:269-81.

3. Qian MB, Utzinger J, Keiser J, Zhou XN. Clonorchiasis. Lancet. 2016;387: $800-10$.

4. Petney TN, Andrews RH, Saijuntha W, Wenz-Mücke A, Sithithaworn P. The zoonotic, fish-borne liver flukes Clonorchis sinensis, Opisthorchis felineus and Opisthorchis viverrini. Int J Parasitol. 2013;43:1031-46.

5. Qian MB, Chen YD, Yan F. Time to tackle clonorchiasis in China. Infect Dis Poverty. 2013;2:4.

6. Sripa B, Kaewkes S, Intapan PM, Maleewong W, Brindley PJ. Food-borne trematodiases in Southeast Asia. epidemiology, pathology, clinical manifestation and control Adv Parasitol. 2010;72:305-50.

7. Hong ST, Fang Y. Clonorchis sinensis and clonorchiasis, an update. Parasitol Int. 2012;61:17-24.

8. Choi DW. Clonorchis sinensis: life cycle, intermediate hosts, transmission to man and geographical distribution in Korea. Arzneimittelforschung. 1984;34:1145-51.

9. Zheng S, Zhu Y, Zhao Z, Wu Z, Okanurak K, Lv Z. Liver fluke infection and cholangiocarcinoma: a review. Parasitol Res. 2017;116:11-9.

10. Chan HH, Lai KH, Lo GH, Cheng JS, Huang JS, Hsu PI, Lin CK, Wang EM. The clinical and cholangiographic picture of hepatic clonorchiasis. J Clin Gastroenterol. 2002:34:183-6.

11. Ona FV, Dytoc JN. Clonorchis-associated cholangiocarcinoma: a report of two cases with unusual manifestations. Gastroenterology. 1991;101:831-9.

12. Osman M, Lausten SB, El-Sefi T, Boghdadi I, Rashed MY, Jensen SL. Biliary parasites. Dig Surg. 1998;15:287-96.

13. Khandelwal N, Shaw J, Jain MK. Biliary parasites: diagnostic and therapeutic strategies. Curr Treat Options Gastroenterol. 2008;11:85-95.

14. Hao Y, Bao W, Jin M, Li Y, Wang F. Painless jaundice caused by Clonorchis sinensis infection: a case report. Korean J Parasitol. 2016;54:323-7.

15. Qiao T, Ma RH, Luo XB, Zheng PM, Luo ZL, Yang LQ. Microscopic examination of gallbladder stones improves rate of detection of Clonorchis sinensis infection. J Clin Microbiol. 2013;51:2551-5.

16. Kaewkong W, Intapan PM, Sanpool O, Janwan P, Thanchomnang T, Laummaunwai P, Lulitanond V, Doanh PN, Maleewong W. Molecular differentiation of Opisthorchis viverrini and Clonorchis sinensis eggs by multiplex real-time PCR with high resolution melting analysis. Korean J Parasitol. 2013;51:689-94.

17. Li S, Shin JG, Cho PY, Kim TI, Hong ST, Hong SJ. Multiple recombinant antigens of Clonorchis sinensis for serodiagnosis of human clonorchiasis. Parasitol Res. 2011;108:1295-302.

18. Chen W, Wang X, Li X, Lv X, Zhou C, Deng C, Lei H, Men J, Fan Y, Liang C, $Y u X$. Molecular characterization of cathepsin B from Clonorchis sinensis excretory/secretory products and assessment of its potential for serodiagnosis of clonorchiasis. Parasit Vectors. 2011;4:149.

19. Ying-Yan Z, Ting-Jun X, Man W, Yue-Yi F, Le L. Prevalence of Clonorchis sinensis infection and effect of albendazole treatment among residents in two communities of Zhongshan City. Zhongguo Xue Xi Chong Bing Fang Zhi Za Zhi. 2018;30:219-21 (in Chinese).

20. Xiao SH, Xue J, Xu LL, Zhang YN, Qiang HQ. Comparative effect of mebendazole, albendazole, tribendimidine, and praziquantel in treatment of rats infected with Clonorchis sinensis. Parasitol Res. 2011;108:723-30.

21. D C, Lim JH, Lee KT, Lee JK, Choi SH, Heo JS, Choi DW, Jang KT, Lee NY, Kim S, Hong ST. Gallstones and Clonorchis sinensis infection: a hospital-based case-control study in Korea. J Gastroenterol Hepatol. 2008;23:e399-404.

22. Qiao T, Ma RH, Luo ZL, Yang LQ, Luo XB, Zheng PM. Clonorcis sinensis eggs are associated with calcium carbonate gallbladder stones. Acta Trop. 2014; 138:28-37. 
23. Tang ZL, Huang Y, Yu XB. Current status and perspectives of Clonorchis sinensis and clonorchiasis: epidemiology, pathogenesis, omics, prevention and control. Infect Dis Poverty. 2016;5:71.

24. Kim YH. Pancreatitis in association with Clonorchis sinensis infestation: $C T$ evaluation. AJR Am J Roentgenol. 1999;172:1293-6.

25. D C, Hong ST. Imaging diagnosis of clonorchiasis. Korean J Parasitol. 2007; 45:77-85.

26. Choi JH, Kim JH, Kim CH, Jung YK, Yeon JE, Byun KS, Kim I. Pancreatic mucinous cystadenoma of borderline malignancy associated with Clonorchis sinensis. Korean J Intern Med. 2015;30:398-401.

27. Oh JK, Lim MK, Yun EH, Cho H, Park EY, Choi MH, Shin HR, Hong ST. Control of clonorchiasis in Korea: effectiveness of health education for community leaders and individuals in an endemic area. Tropical Med Int Health. 2014; 19:1096-104.

Ready to submit your research? Choose BMC and benefit from:

- fast, convenient online submission

- thorough peer review by experienced researchers in your field

- rapid publication on acceptance

- support for research data, including large and complex data types

- gold Open Access which fosters wider collaboration and increased citations

- maximum visibility for your research: over $100 \mathrm{M}$ website views per year

At $\mathrm{BMC}$, research is always in progress.

Learn more biomedcentral.com/submissions 